\title{
The Impact of Stress-Coping Strategies and the Severity of Psoriasis on Self-Esteem, Illness Acceptance and Life Satisfaction
}

\author{
Beata Kowalewska (D) · Elżbieta Krajewska-Kułak · Marek Sobolewski
}

Received: October 20, 2021 / Accepted: December 16, 2021 / Published online: January 18, 2022

(C) The Author(s) 2022

\begin{abstract}
Introduction: The visibility of skin lesions is a significant burden for patients with psoriasis, who experience social hostility as well as many emotional and psychological problems. The recurrent nature of cutaneous manifestations and their location are also a source of emotional distress, which in turn is one of the main factors that intensifies skin lesions in these patients. The aim of the study was to assess the impact of the severity of psoriasis and stress-coping strategies on general psychometric measures in the affected patients.

Methods: The study used a short demographic questionnaire, Psoriasis Area and Severity Index (PASI), and four standardised general psychometric tools: Rosenberg Self-Esteem Scale (SES), Satisfaction With Life Scale (SWLS), Coping Inventory for Stressful Situations (CISS) and Acceptance of Illness Scale (AIS). A total of 111 patients participated in the study.
\end{abstract}

Results: The mean PASI score was 14.0 (12.1-15.9). The mean SWLS score was below average, i.e., 18.5 (17.3-19.7), and the SES score-26.8 points (26.1-27.5)—indicated selfesteem slightly above average among patients with psoriasis. The mean stress-coping level measured with CISS was 53.6 (51.9-55.2) for the task-oriented strategy (TOS), 46.2 (43.8-48.6) for the emotion-oriented strategy (EOS) and 50.1 (48.5-51.8) for the avoidance-oriented strategy (AOS). Higher PASI was associated with lower illness acceptance among men $(r=0.48)$ and lower self-esteem among women $(r=0.44)$. The level of life satisfaction was lower in respondents with higher PASI scores (mainly in the group of women, $r=0.44$ ).

Conclusions: Higher severity of psoriasis (PASI) and greater frequency of emotion-oriented stress-coping mechanisms (CISS) are factors that negatively affect the overall psychophysical condition of respondents.

Keywords: Psoriasis; Quality of life; Illness acceptance; Self-esteem; Life satisfaction; SWLS; CISS; PASI; SES; AIS

B. Kowalewska $(\varangle) \cdot$ E. Krajewska-Kułak

The Department of Integrated Medical Care,

Medical University in Białystok, 7A MC

Skłodowskiej Str., 15-096 Białystok, Poland

e-mail: beata.kowalewska@umb.edu.pl

M. Sobolewski

Faculty of Management, Rzeszow University of

Technology, Rzeszow, Poland 


\section{Key Summary Points}

\section{Why carry out this study?}

Psoriatic skin lesions are the cause of difficulty accepting the illness, reduced life quality and psychosocial problems.

Psoriasis may be associated with organ complications, mental disorders and increased socioeconomic costs.

It was assumed that the stress-coping strategies and severity of skin lesions would determine the individual level of self-esteem and perceived satisfaction with life. Thus, it was expected that the more severe psoriatic skin lesions were, the worse coping with stress and lower self-esteem and life satisfaction would be in the affected patients and that these factors would be correlated with low acceptance of the disease. These phenomena would be modified by sociodemographic variables and location of skin lesions.

\section{What was learned from the study?}

Increased severity of psoriatic lesions and a greater frequency of emotion-oriented stress-coping mechanisms have a negative impact on the general psychophysical condition of patients with psoriasis.

Increased severity of psoriatic lesions correlated with lower illness acceptance among men and lower self-esteem among women.

Life satisfaction was lower in respondents with severe skin lesions and higher PASI scores.
Therefore, despite the well-known negative impact of psoriasis on various spheres of patients' lives, future research is needed to verify whether these phenomena are modified as a result of social changes. It is also worth searching for general life quality indicators affected by psoriasis and attempting to improve them to reduce the negative impact of psoriasis on the lives of these patients. Perhaps the new data will allow for the evaluation of psychotherapeutic and social support for patients with psoriasis.

\section{INTRODUCTION}

Psoriasis is one of the most burdensome and incurable dermatoses. It is characterised by high recurrence rates. Usually, the skin, nails and joints are involved [1]. The global incidence is about $2 \%$, with about $2-3 \%$ of affected population in Poland [2-5]. Among the many predisposing factors, emotional stress, trauma, immune factors, diet, certain pharmacological preparations and genetic factors play important roles [6-10]. It is the visibility of lesions and their frequent recurrence and exacerbation that evoke negative emotions and reactions towards psoriatic patients. People with psoriasis often experience social rejection and marginalisation as they are perceived as worthless, neglected individuals burdened with an infectious disease. As a result, they are not only depreciated, but also stigmatized, experience significant emotional stress and develop disturbed self-concept and a distorted perception of their own body image. This in turn gives rise to psychosocial problems triggered by the negative social response to their appearance [11-16].

In a world where imperfection is unacceptable and the cult of flawless, young appearance, as well as a perfect body and glowing healthy complexion is promoted, the feeling of being different, inferior or unacceptable because of one's appearance contributes to the sense of existential meaninglessness and arouses negative emotions directed towards oneself, the 
disease and the surrounding society. The stress experienced by patients with psoriasis paradoxically intensifies the symptoms, including the cutaneous ones, thus deteriorating their general and emotional state and further intensifying distress and negative emotions that were difficult to cope with already before and generating or escalating the fear of stigmatisation [13-17].

It should be emphasised that patients with psoriasis and other chronic dermatoses, who experience frequent exacerbations of skin lesions, or whose psoriatic lesions fail to respond to treatment or their location is critical for the patient, when combined with psychosocial problems, including social relationships, show a lack of disease acceptance, reduced quality of life and low self-esteem. Furthermore, the above phenomena contribute to the coexistence of a number of somatic complications, such as obesity, depression [17-23], sexual disorders [24, 25], cardiovascular diseases and susceptibility to various addictions (use of stimulants helps reduce emotional stress) [21-23].

The aim of the study was to assess:

- the impact of the severity of the disease and stress-coping strategies on general psychometric measures, including illness acceptance, self-esteem and life satisfaction, in patients with psoriasis;

- illness acceptance, life satisfaction and selfesteem in the study group of psoriatic patients;

- the impact of sociodemographic variables on the general psychometric measures of the quality of life (SES, SWLS, AIS).

It was assumed that the individual level of self-esteem and the perceived satisfaction with life will depend on the severity of skin lesions. Thus, it was concluded that the more severe the psoriatic skin lesions are, the lower the self-esteem and life satisfaction will be, and these will be correlated with low acceptance of the disease. These phenomena will intensify with decreasing or increasing severity of skin lesions and will be modified by sociodemographic variables and the location of these skin lesions. The discussed phenomena are important to this study because of the significant correlation between psoriasis and psychosomatic and social complications in this group of patients.

It should be emphasised that patient's failure to choose proper stress-coping strategies and emotional overreaction, often inadequate to the situation, are factors that intensify the symptoms, thus increasing the PASI scores. Therefore, it can be assumed that the above phenomena will be associated with worsening psoriatic skin lesions in stressful situations and will affect the general psychometric measures of self-esteem and disease acceptance, which are indirect determinants of the quality of life of these patients.

Although there already is some research on this subject, it should be continued to monitor potential modifications in the described phenomenon resulting from socio-cultural changes.

Our study is limited by the lack of data on the detailed localization of psoriatic lesions, including sensitive areas (e.g., genitals, face, nails), and PsA, which could shape the psychological responses of patients. Such data will be considered when planning another study.

\section{METHODS}

\section{Participants}

The study was conducted among 111 patients with psoriasis vulgaris ( $46.8 \%$ women, $53.2 \%$ men) treated in the Dermatology and Medical Cosmetology Centre in Bialystok run by Prof. Wiaczesław Niczyporuk, MD, PhD, and the Dermatology and Medical Cosmetology Centre run by Piotr Aleksiejczuk, MD, PhD.

Diagnosis of moderately severe plaque psoriasis (PASI 10-50) lasting at least 6 months, no mental illness and consent to participate in the study were the inclusion criteria. Other types of psoriasis and psoriatic arthritis, mental diseases, the use of psychotropic drugs during the week before the study, $<6$ month duration of plaque psoriasis and lack of consent to participate in the study were exclusion criteria.

Diagnosis of moderately severe plaque psoriasis and consent to participate in the study 
were inclusion criteria. The study was conducted in January and February 2020. The outbreak of the COVID-19 pandemic prevented the implementation of the initial study design, i.e., collection of at least 200 fully completed questionnaires. Due to the epidemiological threat and the introduction of restrictions, we ultimately attempted to collect at least 100 fully completed questionnaires. A total of 200 questionnaires were distributed, some of which were not returned. Incomplete questionnaires and questionnaires abandoned during filling out were also rejected. The response rate was 55.5\% (111 questionnaires) and the bounce rate was $44.5 \%$ (89 questionnaires).

The respondents received paper questionnaires with instructions on how to complete them. The questionnaires were completed by the respondents on their own or with the help of a member of the research team in the office where the research was carried out. Those who wished to complete the questionnaire at home were additionally provided with an addressed and stamped envelope for returning the questionnaire (to facilitate the return of the questionnaire). Furthermore, the interviewer discussed the instructions for completing the questionnaire and provided a telephone contact to one of the team members in case any doubts or inquiries arose during questionnaire completion in a home setting.

\section{Ethics Guidelines}

The research conforms with the Good Clinical Practice guidelines, and the procedures followed were in accordance with the Helsinki Declaration of 1975, as revised in 2000 (concerning the ethical principles for the medical community and forbidding release of the patient's name and initials or the hospital evidence number). The study was reviewed and approved by the Bioethics Committee of the Medical University in Białystok (statute no. R-I-002/285/2018). Informed consent was obtained from all individual participants included in the study.

\section{Measures}

The study used a short original questionnaire and four standardised general psychometric tools: Satisfaction With Life Scale (SWLS) by Diener, Emmons, Larsen and Griffin [26] in the Polish adaptation by Juczyński [27], Rosenberg's Self-esteem Scale (SES) in the Polish adaptation by Dwonkowska, Lachowicz-Tabaczek and Łaguna [28], Coping Inventory for Stressful Situations (CISS) by Endler and Parker [29-31] in the Polish adaptation by Strelau et al. [32] and Acceptance of Illness Scale (AIS) developed by Felton et al. [33] in the Polish adaptation by Juczyński [27].

\section{Original Questionnaire}

The questionnaire contained sociodemographic questions (sex, age, marital status, education, place of residence) and also asked about the extent of skin lesions.

\section{Psoriasis Area and Severity Index (PASI)}

PASI is an objective measure as it does not consider patient's subjective feelings but provides measurable data on the type of symptoms and the extent of psoriatic lesions. The score may range from 0 to 72 , with an increasing score corresponding to increasing severity of psoriasis. The following scoring system for the severity of psoriasis was adopted: mild $<10$, moderate $10-50$ and severe $\geq 51 \quad[34,35]$. Patients with moderately severe psoriasis participated in this study.

\section{Coping Inventory of Stressful Situations (CISS)}

CISS is a questionnaire that diagnoses stresscoping styles. It consists of 48 statements (16 in each of the 3 categories) that concern different behaviours undertaken by people in difficult and stressful situations, which are assessed using a 5-point frequency scale (from 1 to 5). The scores are classified into three categories (coping strategies): TOS-task-oriented style 
(the person focuses on completing tasks); EOSemotion-oriented style (the person focuses on their own experiences); AOS-avoidance-oriented style (the person denies the existence of a stressful situation). The latter scale contains two subscales: distraction (D)_engaging in substitute activities; social diversion (SD)—seeking contact with other people. Respondents can score from 16 to 80 in each of the three subscales by summing the scores according to the key [32].

\section{Acceptance of Illness Scale (AIS)}

AIS comprises eight statements on poor health, disease-imposed limitations, sense of dependence on others and decreased self-esteem. The respondents define their attitude to each statement on a 5-point scale, where 1 means "I strongly agree" and corresponds to poor disease acceptance and 5 means "I strongly disagree" and indicates acceptance of the disease. A score ranges from 8 to 40 can be obtained. The higher the score is, the better the respondent's adjustment to the disease [27].

\section{Satisfaction With Life Scale (SWLS)}

SWLS was used to measure the level of life satisfaction. The scale contains five statements on satisfaction with one's own life, which are rated on a scale from 1 (completely disagree) to 7 (completely agree). The scores for the individual statements are summed; the respondent may obtain a score from 5 to 35 , with a higher score indicating higher satisfaction with life. The obtained results are converted into sten scores, where: a sten score of 1-4 means low, 5-6 average and 7-10 high [27].

\section{Rosenberg Self-Esteem Scale (SES)}

The overall level of self-esteem was measured using the Self-Esteem Scale (SES). The scale consists of ten statements rated by the respondent on a point scale from 1 (strongly agree) to 4 (strongly disagree). The respondent can obtain a score from 10 to 40. The obtained results are then converted using sten norm tables, where a sten score 1-2 indicates very low, 3-4 low, 5-6 average, 7-8 high and 9-10 very high satisfaction [28].

\section{Statistical Analysis}

The obtained results were analysed statistically using the Statistica 13 software. The distribution of psychometric measures in the total study population was presented in the form of descriptive statistics (arithmetic mean with 95\% confidence interval, standard deviation, minimum and maximum).

The significance of inter-group differences was assessed using the ANOVA test, while the linear correlation coefficient was used to assess relations between measurable features.

Regression analysis was also used to assess the impact of PASI and CISS measures on life satisfaction.

The following demographic and clinical factors were also included in regression analysis:

- gender;

- age;

- education;

- disease duration;

- presence of lesions at the time of completing the questionnaire.

Statistically significant factors were selected using the stepwise regression method [36, 37].

A $p$-value $<0.05$ was considered statistically significant in all analyses $[36,37]$.

\section{RESULTS}

We assessed the impact of the severity of psoriatic lesions (PASI) and stress-coping strategies (CISS) on the general quality of life (SWLS, SES, AIS).

First, we present the characteristics of the distribution of the measures analysed throughout the study population. 


\section{Distribution Characteristics Throughout the Sample}

The mean PASI score in the study population was 14.0 , which corresponds to moderate psoriatic skin lesions (possible range for moderately severe psoriasis: 10-50). The mean SWLS score was slightly below average, i.e., 18.5 (the score may range from 5 to 35). On the other hand, the mean SES score of 26.8 obtained in the study population indicates self-esteem slightly above average (the score may range from 10 to $40)$.

The mean CISS score for stress coping ability in the total population surveyed was 53.6 for TOS, 46.2 for EOS and 50.1 for AOS (with a possible score of 16-80 for each category), with a score of 21.7 for the D strategy and 16.5 for the SD strategy (Table 1). Most respondents used the avoidance strategy (65.8\%), while the task-oriented style was used by only $16.2 \%$ of respondents. Although we did not present detailed classifications because of the limited length of the paper, we decided to signal this interesting aspect.

\section{Quality of Life (QoL) and Selected Demographic and Clinical Factors}

We verified whether the general measures of quality of life were influenced by certain demographic and clinical factors, such as gender, age, education, disease duration and the presence of psoriasis at the time of the survey.

Significantly higher level of illness acceptance $(p=0.0040)$ and self-esteem $(p=0.0220)$ among men as well as slightly higher EOS and SD scores among women were the only statistically significant results (Table 2 ).

However, there is no relationship between the quality of life (QoL) measured with general psychometric tools (AIS, SWLS and SES) and education, age, disease duration or the extent of psoriatic lesions.

\section{Severity of Psoriatic Lesions and Psychometric Measures}

We subsequently performed a preliminary analysis of the relationship between PASI scores and quality of life. To this end, a table of linear correlation coefficients with an assessment of their statistical significance was prepared. Due to the gender-related differences in the general QoL measures, we present the correlation coefficients calculated for both the entire population and separately for each gender.

Our findings are quite interesting; higher PASI was associated with lower disease acceptance among men $(r=0.48)$ and with lower selfesteem among women $(r=0.44)$. Also, the level of life satisfaction was lower in respondents with higher PASI, mainly in the group of women $(r=0.44)$, while the correlation among men, although statistically significant, was weaker $(r=0.27)$ (Table 3).

Selected relationships are presented in the scatter diagrams (Fig. 1).

These results were the reason to consider not only the gender factor but also the interaction between gender and PASI in the regression analysis.

\section{Impact of PASI and CISS on the Quality of Life-Regression Models}

Three regression models were constructed to investigate the impact of PASI (severity of psoriasis) and stress-coping strategies (CISS) on general QoL measures (AIS, SWLS and SES). In each of the models, in addition to PASI and CISS, control factors, such as sex, age, education, disease duration and the extent of psoriatic lesions, were introduced as independent variables. Then, using the stepwise regression procedure, a search for an optimal model containing only statistically significant factors was made. The effects of these activities for three models, i.e., SWLS (Table 4), SES (Table 5) and AIS (Table 6), as dependent variables are presented below. The constructed models account for 30.7-39.2\% of AIS, SES and SWLS variability.

PASI and EOS were statistically significant factors in all models. A negative regression 
Table 1 Characteristics of the distribution of the severity of psoriatic lesions and psychometric measures throughout the study population

\begin{tabular}{llcll}
\hline Features & Mean $(\mathbf{9 5 \%} \mathbf{C I})$ & SD & Median & Range \\
\hline PASI & $14.0(12.1-15.9)$ & 10.1 & 11.3 & $1.7-49.2$ \\
CISS-TOS & $53.6(51.9-55.2)$ & 8.7 & 54 & $16-78$ \\
CISS-EOS & $46.2(43.8-48.6)$ & 12.7 & 48 & $16-71$ \\
CISS-AOS & $50.1(48.5-51.8)$ & 8.7 & 50 & $16-69$ \\
CISS-D & $21.7(20.8-22.5)$ & 4.6 & 22 & $7-32$ \\
CISS-SD & $16.5(15.8-17.1)$ & 3.3 & 16 & $5-25$ \\
SWLS & $18.5(17.3-19.7)$ & 6.5 & 18 & $6-35$ \\
SES & $26.8(26.1-27.5)$ & 3.6 & 27 & $16-36$ \\
AIS & $26.1(24.8-27.4)$ & 6.9 & 27 & $12-38$ \\
\hline
\end{tabular}

PASI Psoriasis Area and Severity Index, SES Rosenberg Self-Esteem Scale, SWLS Satisfaction With Life Scale, AIS Acceptance of Illness Scale, CISS Coping Inventory of Stressful Situations, TOS task-oriented style, EOS emotion-oriented style, $A O S$ avoidance-oriented style: (two subscales), Distraction (D) engaging in substitute activities, Social Diversion (SD) seeking contact with other people

Table 2 AIS, SWLS and SES scores (with 95\% CI) by gender

\begin{tabular}{llll}
\hline QoL measures & \multicolumn{2}{l}{ Gender (male vs. female) } & \multicolumn{1}{c}{$\boldsymbol{p}$} \\
\cline { 2 - 4 } & Female $(\boldsymbol{N}=\mathbf{5 2})$ & $27.8(26.1-29.5)$ & $0.0040^{* *}$ \\
\hline AIS & $24.1(22.2-26.0)$ & $18.7(16.9-20.5)$ & 0.7410 \\
SWLS & $18.3(16.6-20.0)$ & $27.5(26.6-28.4)$ & $0.0220^{*}$ \\
SES & $26.0(24.9-27.0)$ & $53.4(51.0-55.7)$ & 0.7862 \\
CISS-TOS & $53.8(51.5-56.1)$ & $44.2(41.0-47.5)$ & 0.0836 \\
CISS-EOS & $48.4(44.9-52.0)$ & $49.1(46.8-51.3)$ & 0.1737 \\
CISS-AOS & $51.3(48.9-53.8)$ & $21.1(20.0-22.3)$ & 0.1985 \\
CISS-D & $22.3(21.0-23.6)$ & $15.9(15.0-16.7)$ & $0.0404^{*}$ \\
CISS-SD & $17.2(16.2-18.1)$ & $A I S$ Accp & \\
\hline
\end{tabular}

SES Rosenberg Self-Esteem Scale, SWLS Satisfaction With Life Scale, AIS Acceptance of Illness Scale, CISS Coping Inventory of Stressful Situations, TOS task-oriented style, EOS emotion-oriented style, $A O S$ avoidance-oriented style: (two subscales), Distraction (D) engaging in substitute activities, Social Diversion (SD) seeking contact with other people $p \geq 0.05$ the effect is not statistically significant, ${ }^{*} p<0.05$ statistically significant relationship, ${ }^{* *} p<0.01$ highly significant relationship, ${ }^{* *} p<0.001$ very highly statistically significant relationship

coefficient for these variables meant that the increased severity of psoriatic lesions and higher frequency of emotional responses to stressful situations were factors that had a negative impact on the overall psychophysical condition. It can be concluded from the comparison of $\beta$ coefficients that the emotional aspect (measured with EOS) was of greater importance. 
Table 3 Impact of the severity of psoriatic lesions on general psychometric measures by gender-linear correlation coefficients (with $p$ value in brackets)

\begin{tabular}{|c|c|c|c|}
\hline \multirow{2}{*}{ QoL measures } & \multicolumn{3}{|c|}{ Gender (male vs. female) } \\
\hline & $\begin{array}{l}\text { Female } \\
\text { PASI }\end{array}$ & Male & Total \\
\hline AIS & $-0.16(p=0.2507)$ & $-0.48\left(p=0.0001^{* * *}\right)$ & $-0.33\left(p=0.0004^{* * *}\right)$ \\
\hline SWLS & $-0.44\left(p=0.0011^{* *}\right)$ & $-0.27\left(p=0.0365^{*}\right)$ & $-0.35\left(p=0.0002^{* * *}\right)$ \\
\hline SES & $-0.42\left(p=0.0021^{* *}\right)$ & $-0.23(p=0.0846)$ & $-0.37\left(p=0.0001^{* * *}\right)$ \\
\hline
\end{tabular}

PASI Psoriasis Area and Severity Index, SES Rosenberg Self-Esteem Scale, SWLS Satisfaction With Life Scale, AIS Acceptance of Illness Scale

$p \geq 0.05$ the effect is not statistically significant, ${ }^{*} p<0.05$ statistically significant relationship, ${ }^{* *} p<0.01$ highly significant relationship, ${ }^{* * *} p<0.001$ very highly statistically significant relationship

In turn, the higher the AOS (for SWLS) and TOS (for SES and AIS) score, the worse the psychophysical condition was. Demographic and clinical factors (except for PASI) had no impact on SWLS; the SES score were higher for patients with higher education, and disease acceptance was higher among men.

\section{DISCUSSION}

People today are very sensitive about their appearance and body image. Therefore, chronic diseases such as psoriasis, characterised by high recurrence and visible skin lesions, are a particular burden for patients in terms of negative social perception and body image. Awareness of an imperfect appearance unaccepted by society translates into stress as well as psychological and social problems [13]. The location of skin lesions, especially when they involve body parts that are often exposed or important from the patient's point of view, or they cover extensive parts of the body, and the severity of skin lesions, which affect the broadly understood quality of life of these patients, also play a critical role in this process [13].

Abrok et al. [38] assessed studies on the relationship between the severity of skin lesions (PASI) and the quality of life (DLQI) in patients with plaque psoriasis who received biological treatment. They found that clinically remarkable skin improvement may not necessarily translate into improved QoL.
On the other hand, Çakmur et al. [39] reported reduced QoL in patients with psoriasis unrelated to the PASI score.

Reich et al. [40] reported a mean severity of psoriasis (PASI) of $17.1 \pm 10.0$. The researchers also found a weak yet statistically significant correlation between the patients' rating of psoriasis severity and the objective measurement of psoriasis severity using the PASI scale $(\rho=0.37$, $p<0.001$ ).

In our study, the mean PASI score was 14.0 (12.1-15.9), which indicates moderate severity of psoriatic lesions.

Eskin et al. [41] showed that psoriatic patients had lower life satisfaction than nonpsoriatic controls. Poor life satisfaction was reported by Kowalewska et al. [42]; interestingly, it was slightly more common among men than women $(p=0.147)$.

Solovan et al. [43] showed, on the other hand, a significant correlation between psoriasis and reduced life satisfaction of respondents in terms of body, sexual, social, family and professional satisfaction as well as satisfaction with one's own health $(p<0.01)$.

Basińska and Drozdowska [44] showed that life satisfaction in psoriatic patients is influenced by the affected surface area and emotional intelligence.

Reszutek et al. [45] demonstrated that the negative self-image in psoriatic patients resulted in the lowest satisfaction. In this study, life satisfaction did not correlate with the age of 

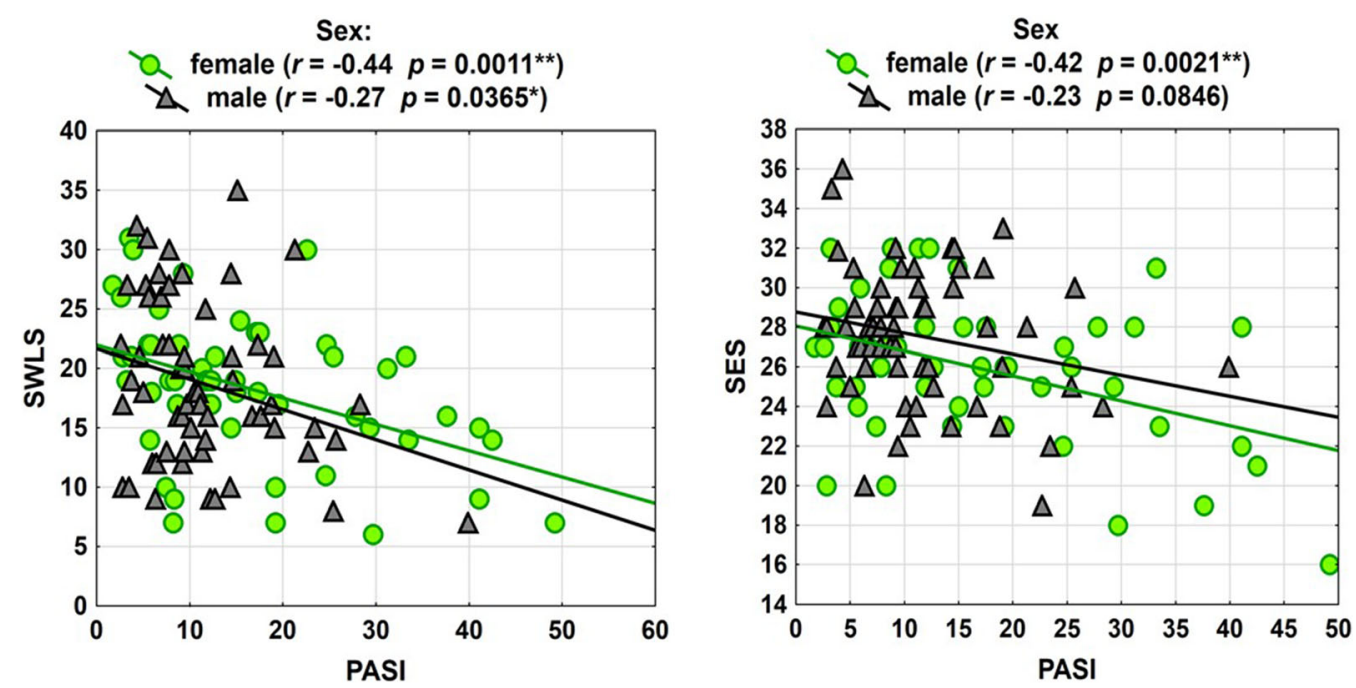

Fig. 1 PASI-SWLS, PASI-SES correlations

Table 4 Regression model for SWLS

\begin{tabular}{|c|c|c|c|}
\hline \multirow[t]{2}{*}{ Independent factors } & \multicolumn{3}{|c|}{$\begin{array}{l}\text { SWLS } \\
R^{2}=39.2 \%, F=23.0 p=0.0000^{* * *}\end{array}$} \\
\hline & $B(95 \% \mathrm{CI})$ & $p$ & $\beta$ \\
\hline PASI & $-0.144(-0.244 ;-0.043)$ & $0.0054^{* *}$ & -0.23 \\
\hline CISS-EOS & $-0.278(-0.362 ;-0.193)$ & $0.0000^{* * *}$ & -0.55 \\
\hline CISS-AOS & $0.251(0.133 ; 0.369)$ & $0.0001^{* * *}$ & 0.34 \\
\hline
\end{tabular}

$R^{2}=$ coefficient of determination, $F=$ test statistic and $p$ value for significance of whole model, $B$ : regression coefficient with $95 \% \mathrm{CI}, p$ value for significance of each regression coefficient, $\beta$ : standardized regression coefficient

PASI Psoriasis Area and Severity Index, SWLS Satisfaction With Life Scale, CISS Coping Inventory of Stressful Situations, $E O S$ emotion-oriented style, $A O S$ avoidance-oriented style

$p \geq 0.05$ effect is not statistically significant, ${ }^{*} p<0.05$ statistically significant relationship, ${ }^{* *} p<0.01$ highly significant relationship, ${ }^{* * *} p<0.001$ very highly statistically significant relationship

respondents $(p>0.05)$, but it was significantly higher among those in relationships $(p<0.01)$.

Soliman [46] found that $83.4 \%$ of the respondents were convinced that people noticed their skin lesions. Furthermore, the study group was characterised by low satisfaction with life (a mean score of 21.2) and reduced QoL resulting in lower life satisfaction. At the same time, increased disease acceptance was associated with greater life satisfaction.

Similarly, Kowalewska et al. [47] found that psoriatic patients with a higher level of illness acceptance also showed greater satisfaction with life.

Kouris et al. [48] found a statistically significant difference in self-esteem (SES) between psoriatic patients and healthy controls $(p<0.0001)$, with lower self-esteem among women than men. Hassani et al. [49] and Alarina et al. [50] also noted lower self-esteem among psoriatic patients [50].

Brihan et al. [51] found that the severity of psoriasis reduced self-esteem (SES), which was in turn correlated with lower perceived QoL. The differences in self-esteem between patients 
Table 5 Regression model for SES

\begin{tabular}{|c|c|c|c|}
\hline \multirow[t]{2}{*}{ Independent factors } & \multicolumn{3}{|c|}{$\begin{array}{l}\text { SES } \\
R^{2}=38.5 \%, F=16.6 p=0.0000^{* * *}\end{array}$} \\
\hline & $B(95 \% \mathrm{CI})$ & $p$ & $\beta$ \\
\hline PASI & $-0.091(-0.149 ;-0.033)$ & $0.0024^{* *}$ & -0.25 \\
\hline CISS-TOS & $0.102(0.037 ; 0.167)$ & $0.0025^{* *}$ & 0.25 \\
\hline CISS-EOS & $-0.146(-0.193 ;-0.099)$ & $0.0000^{* * *}$ & -0.51 \\
\hline Education (higher vs. other) & $1.194(0.008 ; 2.381)$ & $0.0486^{*}$ & 0.16 \\
\hline \multicolumn{4}{|c|}{$\begin{array}{l}R^{2}=\text { coefficient of determination, } F=\text { test statistic and } p \text { value for significance of whole model, } B \text { : regression coefficient with } \\
95 \% \mathrm{CI}, p \text { value for significance of each regression coefficient, } \beta \text { : standardized regression coefficient } \\
\text { PASI Psoriasis Area and Severity Index, SES Rosenberg Self-Esteem Scale, CISS Coping Inventory of Stressful Situations, } \\
\text { TOS task-oriented style, EOS emotion-oriented style }\end{array}$} \\
\hline
\end{tabular}

Table 6 Regression model for AIS

\begin{tabular}{|c|c|c|c|}
\hline \multirow[t]{2}{*}{ Independent factors } & \multicolumn{3}{|c|}{$\begin{array}{l}\text { AIS } \\
R^{2}=30.7 \%, F=11.8, p=0.0000^{* * *}\end{array}$} \\
\hline & $B(95 \% \mathrm{CI})$ & $p$ & $\beta$ \\
\hline PASI & $-0.130(-0.247 ;-0.013)$ & $0.0302^{*}$ & -0.19 \\
\hline CISS-TOS & $0.272(0.141 ; 0.403)$ & $0.0001^{* * *}$ & 0.34 \\
\hline CISS-EOS & $-0.181(-0.276 ;-0.086)$ & $0.0003^{* * *}$ & -0.34 \\
\hline Sex (male vs. female) & $2.426(0.150 ; 4.703)$ & $0.0369^{*}$ & 0.18 \\
\hline
\end{tabular}

$R^{2}=$ coefficient of determination, $F=$ test statistic and $p$ value for significance of whole model, $B=$ regression coefficient with 95\% CI, $p$ value for significance of each regression coefficient, $\beta=$ standardized regression coefficient

PASI Psoriasis Area and Severity Index, AIS Acceptance of Illness Scale, CISS Coping Inventory of Stressful Situations, TOS task-oriented style, EOS emotion-oriented style

$p \geq 0.05$ the effect is not statistically significant, ${ }^{*} p<0.05$ statistically significant relationship, ${ }^{* *} p<0.01$ highly significant relationship, ${ }^{* * *} p<0.001$ very highly statistically significant relationship

with severe psoriasis and those with mild forms were also statistically significant.

Bitan et al. [52] showed that respondents with low self-esteem (measured with SES) also experienced overlapping anxiety and depression due to their skin disease (psoriasis) $(p=0.001)$.

Nazik found statistically significant relationships between psoriasis and decreased self-esteem and disturbed body image ( $p=0.001)$ [53].

Słomian et al. [54] demonstrated a significantly lower level of self-esteem in patients with psoriasis compared to healthy controls. Reich et al. [55] showed that $49 \%$ of psoriatic patients reported a strong negative impact of the disease on their lives, with lower self-esteem in $40 \%$ of respondents [55]. Patients with reduced self-esteem were significantly younger and more often professionally active.

Our analysis of the impact of psoriasis on non-psoriasis-specific psychometric measures that determine the QoL in this group of patients showed that the mean level of life satisfaction (SWLS) in the study group was below average (a 
score of 18.5). However, the self-esteem score (SES) in the study group was 26.8, which is slightly above average.

We also assessed the impact of selected demographic factors (gender, age, education and presence of lesions) on the overall SWLS and SES scores. We found a statistically significant result for self-esteem, with a higher level of self-esteem presented by men $(p=0.0220)$ and no statistical significance for SWLS $(p=0.7410)$. Women had lower SES (26.0) and SWLS scores (18.3) than men (SES score of 27.5, SWLS score of 18.7).

Other demographic variables, such as age, education and presence of lesions, were not statistically significantly correlated with self-esteem (SES) or life satisfaction (SWLS) among the respondents.

Our study found a statistically significant result for illness acceptance, with a significantly higher level of acceptance among men $(p=0.0040)$. Women showed lower disease acceptance (mean score of 24.1) than men (27.5). The remaining demographic variables, such as the presence of lesions, age and education, had no statistically significant impact on the level of disease acceptance in the study group of patients. Furthermore, higher PASI was associated with lower illness acceptance among men $(r=0.48, p=0.0001)$ and with lower selfesteem among women $(r=0.44, p=0.0021)$. Also, the level of life satisfaction was lower in patients with higher PASI, especially in the women $(r=0.44, p=0.0011)$, whereas the correlation among men, although statistically significant, was weaker $(r=0.27, p=0.0365)$.

Psoriatic respondents included in the study by Słomian et al. [54] presented significantly higher indices for emotion- and avoidance-oriented coping strategies, lower indices for taskoriented coping strategies and a significantly lower level of self-esteem compared to healthy individuals.

Noormohammadpour et al. [55] included 200 psoriatic patients in their study. Patients with genital involvement had the most negative perception of their disease and the worst coping strategy as measured with CISS.

Our respondents were more likely to use the emotion-oriented stress-coping strategy.
Furthermore, the emotional attitude to stressful situations increased with increasing severity of psoriasis.

\section{CONCLUSIONS}

No correlations were found between the quality of life measured with SES, AIS and SWLS and education, age, disease duration and extent of psoriatic lesions. Disease acceptance and selfesteem were statistically higher in the men's group. The analysis of the correlation between PASI and general QoL measures (SWLS, SES, AIS) showed that higher PASI was associated with lower disease acceptance among men $(r=0.48)$ and lower self-esteem among women $(r=0.44)$. The level of satisfaction with life was lower in the study group of patients with higher PASI and showed a correlation in both the women's $(r=0.44)$ and men's $(r=0.27)$ groups. In terms of coping with stressful situations, the emotional aspect (EOS) was of greater importance. In turn, higher AOS (for SWLS) and TOS (for SES and AIS) scores were associated with poorer psychophysical condition. Demographic and clinical factors (except for PASI) had no effect on SWLS; higher SES scores were found for patients with higher education, and higher disease acceptance was reported for men.

\section{ACKNOWLEDGEMENTS}

The authors thank the patients who participated in the survey.

Funding. This study and the Rapid Service Fee were funded by Medical University of Bialystok, Poland. All authors had full access to all of the data in this study and take complete responsibility for the integrity of the data and accuracy of the data analysis. Neither honoraria nor other forms of payments were made for authorship.

Authorship. All named authors meet the International Committee of Medical Journal Editors (ICMJE) criteria for authorship for this manuscript, take responsibility for the integrity 
of the work as a whole, and have given final approval to the version to be published.

Disclosures. Beata Kowalewska, Elżbieta Krajewska-Kułak and Marek Sobolewski have nothing to disclose.

Compliance with Ethics Guidelines. The research conforms with Good Clinical Practice guidelines, and the procedures followed were in accordance with the Helsinki Declaration of 1975 , as revised in 2000 (concerning the ethical principles for the medical community and forbidding release of the patient's name and initials or the hospital evidence number). The study was reviewed and approved by the Bioethics Committee of the Medical University in Białystok (statute no. R-I-002/285/2018). Informed consent was obtained from all individual participants included in the study.

Data Availability. The datasets generated during and/or analyzed during the current study are available from the corresponding author on reasonable request.

Author Contributions. Beata Kowalewska: was a major contributor in writing the manuscript and supervised this study and was responsible for patient recruitment, data collection, data analysis and drafting the manuscript. Elżbieta Krajewska-Kułak was involved in the development of the idea and revised the manuscript critically for important intellectual content. Marek Sobolewski was involved in the development of the idea and revised the manuscript critically for important intellectual content. All authors read and approved the final manuscript.

Open Access. This article is licensed under a Creative Commons Attribution-NonCommercial 4.0 International License, which permits any non-commercial use, sharing, adaptation, distribution and reproduction in any medium or format, as long as you give appropriate credit to the original author(s) and the source, provide a link to the Creative Commons licence, and indicate if changes were made. The images or other third party material in this article are included in the article's Creative Commons licence, unless indicated otherwise in a credit line to the material. If material is not included in the article's Creative Commons licence and your intended use is not permitted by statutory regulation or exceeds the permitted use, you will need to obtain permission directly from the copyright holder. To view a copy of this licence, visit http://creativecommons.org/licenses/by$\mathrm{nc} / 4.0 /$.

\section{REFERENCES}

1. Hong J, Koo B, Koo J. The psychosocial and occupational impact of chronić skin disease. Dermatol Ther. 2008;21:54-9. https://doi.org/10.1111/j.15298019.2008.00170.x.

2. Inanir I, Aydemir O, Gündüz K, Danaci AE, Türel A. Developing a quality of life instrument in patients with psoriasis: the Psoriasis Quality of Life Questionnaire (PQLQ). Int J Dermatol. 2006;45:234-8. https://doi.org/10.1111/j.1365-4632.2005.02448.x.

3. Kong Y, Zhang S, Wu R, Su X, Peng D, Zhao M, Su Y. New insights into different adipokines in linking the pathophysiology of obesity and psoriasis. Lipids Health Dis. 2019;18(1):171. https://doi.org/10. 1186/s12944-019-1115-3.

4. Rendon A, Schäkel K. Psoriasis pathogenesis and treatment. Int J Mol Sci. 2019;20(6):1475. https:// doi.org/10.3390/ijms20061475.

5. Frischknecht L, Vecellio M, Selmi C. The role of epigenetics and immunological imbalance in the etiopathogenesis of psoriasis and psoriatic arthritis. Ther Adv Musculoskelet Dis. 2019;11:17-59. https://doi.org/10.1177/1759720X19886505.

6. Drvar DL, Vlahinić T, Maleš Ž, Turčić P, Čeović R. A modern approach to the treatment of plaque psoriasis. Acta Pharm. 2019;69(4):511-23. https://doi. org/10.2478/acph-2019-0047.

7. Langley RG, Krueger GG, Griffiths CE. Psoriasis: epidemiology, clinical features, and quality of life. Ann Rheum Dis. 2005;64(Suppl 2):ii18-23. https:// doi.org/10.1136/ard.2004.033217.

8. Oji V, Luger TA. The skin in psoriasis: assessment and challenges. Clin Exp Rheumatol. 2015;33(5 Suppl 93):S14-9.

9. Petraškienė R, Valiukevičienė S, Macijauskienė J. Associations of the quality of life and 
psychoemotional state with sociodemographic factors in patients with psoriasis. Medicina. 2016;52(4):238-43. https://doi.org/10.1016/j. medici.2016.07.001.

10. Boehncke WH, Schön MP. Psoriasis. Lancet. 2015;386(9997):983-94. https://doi.org/10.1016/ S0140-6736(14)61909-7.

11. Zięciak T, Rzepa T, Król J, Żaba R. Stigmatization feelings and depression symptoms in psoriasis patients. Psychiatr Pol. 2017;51:1153-63. https:// doi.org/10.12740/PP/68848.

12. Schmid-Ott G, Schallmayer S, Calliess IT. Quality of life in patients with psoriasis and psoriasis arthritis with a special focus on stigmatization experience. Clin Dermatol. 2007;25:547-54. https://doi.org/10. 1016/j.clindermatol.2007.08.008.

13. Zill JM, Dirmaier J, Augustin M, et al. Psychosocial distress of patients with psoriasis: protocol for an assessment of care needs and the development of a supportive intervention. JMIR Res Protoc. 2018;7: e22. https://doi.org/10.2196/resprot.8490.

14. Kostyła M, Tabała K, Kocur J. Illness acceptance degree versus intensity of psychopathological symptoms in patients with psoriasis. Adv Dermatol Allergol. 2013;30:134-9. https://doi.org/10.5114/ pdia.2013.35613.

15. Hrehorów E, Reich A, Szepietowski J. Jakość życia chorych na łuszczycę: zależność od świądu, stresu i objawów depresyjnych. Dermatol Klin. 2007;9: 19-23.

16. Martínez-Ortega JM, Nogueras P, Muñoz-Negro JE, Gutiérrez-Rojas L, González-Domenech P, Gurpegui M. Quality of life, anxiety and depressive symptoms in patients with psoriasis: a case-control study. J Psychosom Res. 2019. https://doi.org/10.1016/j. jpsychores.2019.109780.

17. Gupta MA, Gupta AK. Psychiatric and psychological comorbidity in patients with dermatologic disorders: epidemiology and management. An J Clin Dermatol. 2003;4(12):833-42. https://doi.org/10. 2165/00128071-200304120-00003.

18. Miękoś-Zydek B, Ryglewska A, Lassota-Falczewska M, Czyż P, Kaszuta A. Quality of life in psoriatic patients. Adv Dermatol Allergol. 2006;23(6):273-7.

19. Rapp DA, Brenes GA, Felman SR, et al. Anger and acne: implications for quality of life, patient satisfaction and clinical care. $\mathrm{Br} \mathrm{J}$ Dermatol. 2004;151(1):183-9. https://doi.org/10.1111/j.13652133.2004.06078.x.

20. Zacharie R, Zacharie C, Ibsen H, Morternsen JT, Wulf HC. Dermatology life quality idem: data
Danish inpatients and outpatients. Acta Derm Venerol. 2003. https://doi.org/10.1080/ 000155500750012153.

21. Gerdes S, Zahl VA, Weichenthal M, Mrowietz U. Smoking and alcohol intake in severely affected patients with psoriasis in Germany. Dermatology. 2010;220:38-43. https://doi.org/10.1159/ 000265557.

22. Fortes C, Mastroeni S, Leffondré K, et al. Relationship between smoking and the clinical severity of psoriasis. Arch Dermatol. 2005;141:1580-4. https:// doi.org/10.1001/archderm.141.12.1580.

23. Kirby B, Richards HL, Mason DL, Fortune DG, Main CJ, Griffiths CE. Alcohol consumption and psychological distress in patients with psoriasis. $\mathrm{Br} \mathrm{J}$ Dermatol. 2008;158:138-40. https://doi.org/10. 1111/j.1365-2133.2007.08299.x.

24 TürelErmertcan A, Temeltaş G, Deveci A, et al. Sexual dysfunction in patients with psoriasis. J Dermatol. 2006;33:772-8. https://doi.org/10.1111/j.13468138.2006.00179.x.

25. Dauendorffer JN, Ly S, Beylot-Barry M. Psoriasis and male sexuality. Ann Dermatol Venereol. 2019;146(4):273-8. https://doi.org/10.1016/j. annder.2019.01.021.

26. Diener E, Emmons RA, Larsen RJ, Griffin S. The satisfaction with life scale. J Pers Assess. 1985;49(1): 71-5. https://doi.org/10.1207/s15327752jpa4901_ 13.

27. Juczyński Z. NPPPZ-Narzędzia Pomiaru w Promocji i Psychologii Zdrowia. Pracownia Testów Psychologicznych Polskiego Towarzystwa Psychologicznego, Warszawa 2012.

28. Dzwonkowska I, Lachowicz-Tabaczek K, Łaguna M. Samoocena i jej pomiar. SES. Skala Samooceny Rosenberga. Pracownia Testów Psychologicznych, Warszawa 2008.

29. Endler NS, Parker JDA. Coping Inventory for Stressful Situations (CISS). Manual, Multi-Health Systems, Toronto; 1990.

30. Jaworowska A. CISS. In: Słownik psychologii, red. J. Siuta, KWN, Kraków; 2009. p. 348.

31. Tomczak K. Style radzenia sobie w sytuacji stresowej, przekonanie o własnej skuteczności, nadzieja na sukces u studentów rozpoczynających i kończących studia. Psychoterapia. 2009;2(149):67-79.

32. Strelau J, Jaworowska A, Wrześniewski K, Szczepaniak P. Kwestionariusz Radzenia Sobie w Sytuacjach Stresowych (CISS). Pracownia Testów 
Psychologicznych Polskiego Towarzystwa Psychologicznego, Warszawa; 2013.

33. Felton BJ, Revenson TA. Coping with chronic illness: a study of illness controllability and the influence of coping strategies on psychological adjustment. J Consult Clin Psychol. 1984;52: 343-53. https://doi.org/10.1037//0022-006x.52.3. 343.

34. Bożek A, Reich A. How to assess the severity of psoriasis accurately? Forum Derm. 2016;2(1):6-11.

35. Fredriksson T, Pettersson U. Severe psoriasis-oral therapy with a new retinoid. Dermatologica. 1978;157(4):238-44. https://doi.org/10.1159/ 000250839 .

36. Stanisz A. Przystępny kurs statystyki $z$ zastosowaniem STATISTICA PL na przykładach $z$ medycyny. Tom 1. Wyd. StatSoft Polska, Kraków; 2007.

37. Stanisz A. Przysteppny kurs statystyki z zastosowaniem STATISTICA PL na przykładach $z$ medycyny. Tom 2. Wyd. StatSoft Polska, Kraków; 2007.

38. Abrouk M, Nakamura M, Zhu TH, Farahnik B, Koo J, Bhutani T. The impact of PASI 75 and PASI 90 on quality of life in moderate to severe psoriasis patients. J Dermatol Treat. 2017;28(6):488-91. https://doi.org/10.1080/09546634.2016.1278198.].

39. Çakmur H, Derviş E. The relationship between quality of life and the severity of psoriasis in Turkey. Eur J Dermatol. 2015;25(2):169-76. https://doi. org/10.1684/ejd.2014.2511.

40. Reich A, Welz-Kubiak K, Rams L. Apprehension of the disease by patients suffering from psoriasis. Postepy Dermatol Alergol. 2014;31(5):289-93. https://doi.org/10.5114/pdia.2014.44010.

41. Eskin M, Savk E, Uslu M, Küçükaydoğan N. Social problem-solving, perceived stress, negative life events, depression and life satisfaction in psoriasis. J Eur Acad Dermatol Venereol. 2014;28(11):1553-9. https://doi.org/10.1111/jdv.12355.

42. Kowalewska B, Cybulski M, Jankowiak B, KrajewskaKułak E. Acceptance of illness, satisfaction with life, sense of stigmatization, and quality of life among people with psoriasis: a cross-sectional study. Dermatol Ther. 2020;10:413-30. https://doi.org/10. 1007/s13555-020-00368-w.

43. Solovan C, Marcu M, Chiticariu E. Life satisfaction and beliefs about self and the world in patients with psoriasis: a brief assessment. Eur J Dermatol. 2014;24(2):242-7. https://doi.org/10.1684/ejd. 2014.2295 .
44. Basińska MA, Drozdowska M. Emotional intelligence as an indicator of satisfaction with life of patients with psoriasis. Postepy Dermatol Alergol. 2013;30(6):365-72. https://doi.org/10.5114/pdia. 2013.39435 .

45. Rzeszutek M, Podkowa K, Pięta M, Pankowski D, Cyran-Stemplewska S. Comparative study of life satisfaction among patients with psoriasis versus healthy comparison group: the explanatory role of body image and resource profiles. Qual Life Res. 2021;30(1):181-91. https://doi.org/10.1007/ s11136-020-02621-3.

46. Soliman MM. Feeling of stigmatization and satisfaction with life among Arabic psoriatic patients. Saudi Pharm J. 2020;28(12):1868-73. https://doi. org/10.1016/j.jsps.2020.11.013.

47. Kowalewska B, Jankowiak B, Niedżwiecka B, Krajewska-Kułak E, Niczyporuk W, Khvorik DF. Relationships between the acceptance of illness, quality of life and satisfaction with life in psoriasis. Postepy Dermatol Alergol. 2020;37(6):948-55. https://doi. org/10.5114/ada.2020.92906.

48. Kouris A, Christodoulou C, Stefanaki C, Livaditis M, Tsatovidou R, Kouskoukis C, Petridis A, Kontochristopoulos G. Quality of life and psychosocial aspects in Greek patients with psoriasis: a crosssectional study. An Bras Dermatol. 2015;90(6): 841-5. https://doi.org/10.1590/abd1806-4841. 20154147.

49. Hassani F, Koraei A, Yaghoobi R, Zarea K. An evaluating of the relationship between body image, body satisfaction, depression, marital quality, and self-esteem in patients with psoriasis. Psychol Health Med. 2021;26(4):467-77. https://doi.org/10. 1080/13548506.2020.1766093.

50. Alariny AF, Farid CI, Elweshahi HM, Abbood SS. Psychological and sexual consequences of psoriasis vulgaris on patients and their partners. J Sex Med. 2019;16(12):1900-11. https://doi.org/10.1016/j. jsxm.2019.08.017.

51. Brihan I, Ianoşi SL, Boda D, Hălmăjan A, Zdrîncă M, Fekete LG. Implications of self-esteem in the quality of life in patients with psoriasis. Exp Ther Med. 2020;20(6):202. https://doi.org/10.3892/etm.2020. 9332.

52. Bitan D, Krieger I, Comaneshter D, Cohen AD, Feingold D. The association between the socioeconomic status and anxiety-depression comorbidity in patients with psoriasis: a nationwide populationbased study. J Eur Acad Dermatol Venereol. 2019;33(8):1555-61. https://doi.org/10.1111/jdv. 15651. 
53. Nazik H, Nazik S, Gul FC. Body image, self-esteem, and quality of life in patients with psoriasis. Indian Dermatol Online J. 2017;8(5):343-6. https://doi. org/10.4103/idoj.IDOJ_503_15.

54. Słomian A, Łakuta P, Bergler-Czop B, BrzezińskaWcisło L. Self-esteem is related to anxiety in psoriasis patients: a case control study. J Psychosom Res.
2018;114:45-9.

https://doi.org/10.1016/j.

jpsychores.2018.09.005.

55. Noormohammadpour P, Fakour Y, Nazemei MJ, Ehsani A, Gholamali F, Morteza A, Mokhtari L, Khosrovanmehr N. Evaluation of some psychological factors in psoriatic patients. Iran J Psychiatry. 2015;10(1):37-42. 